\title{
CHANGE IN A TIME OF CRISIS
}

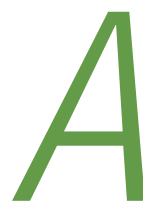

nd just like that, another year passes by. My maternity leave is over and I'm back at the helm of Geoscientist. It wasn't the year I-or anyone-expected. I have a healthy, cheeky one-year-old daughter, and for that I am deeply grateful, but there were few playdates and grandparental bonds were largely built over Zoom. My daughter hasn't interacted with another baby in 8 months and cries at one glance from a stranger. I can't help but wonder if this will have lasting impacts on her social development-and that of an entire generation of children.

The world has changed irrevocably, for better and worse. Over a million people have died from Covid-19, economies have been floored and millions are jobless. While lockdown led to reduced travel, pollution and carbon emissions, the pandemic has also created a flood of single-use plastic waste in the form of discarded Personal Protective Equipment, PPE, that now chokes our environment. In thousands of years' time (if humankind still exists), will future geologists use the lithified remnants of PPE as a chronological marker of this pandemic? Or are our current struggles with the virus simply too brief in the grand scheme of geological time to leave an indelible mark? Though not considered as life themselves, viruses are such an important companion to life that they must surely leave some sort of fingerprint in the geological record-a question explored by Michael A. Rosen on page 8 .

The pandemic has expedited the digital transition, as many adapt to working and studying from home, while attending conferences and even field trips virtually. But living our lives online brings with it a host of ethical concerns. As Estelle Clements discusses on page 16 , the geoscience community could benefit from technological advances by using citizen scientists to collect environmental and landscape data on a vast scale. But, for such an endeavour to succeed, we must first ensure that an ethical framework for data use is in place. The need for track-and-trace systems during the pandemic has led to the formalisation of such frameworks, which could come in handy to the datacollecting geoscientist.

In response to the accelerated digital transition, and the increasing appetite for access to information online, I have been working with the editorial team on proposals for Council's consideration on how to greatly improve and expand the magazine's digital presence. How this is best done is still under discussion, but it is likely to involve a transition to decreased print frequency in 2021. These changes will also save the Society money at a time of financial strain, and reduce our environmental impact. I appreciate that the monthly magazine is cherished by many Fellows and I am sorry that I cannot provide more information on the possible changes at present. We're working hard to finalise the details and we will provide another update in the next issue.

In other news, I'm happy to report that Sarah Day will stay on at the magazine one day per week. If you need to contact either of us, you can do so by emailing geoscientist@geolsoc.org.uk. The magazine will only be staffed Monday to Thursday, so please bear with us. I must offer my sincere thanks to Sarah, as well as to Chief Editors Andy Fleet and David Shilston for their hard work during what has been a remarkably difficult year. In the face of adversity, they've kept the magazine in great shape-and we promise that it will continue to thrive, in one form or another, in the years to come.

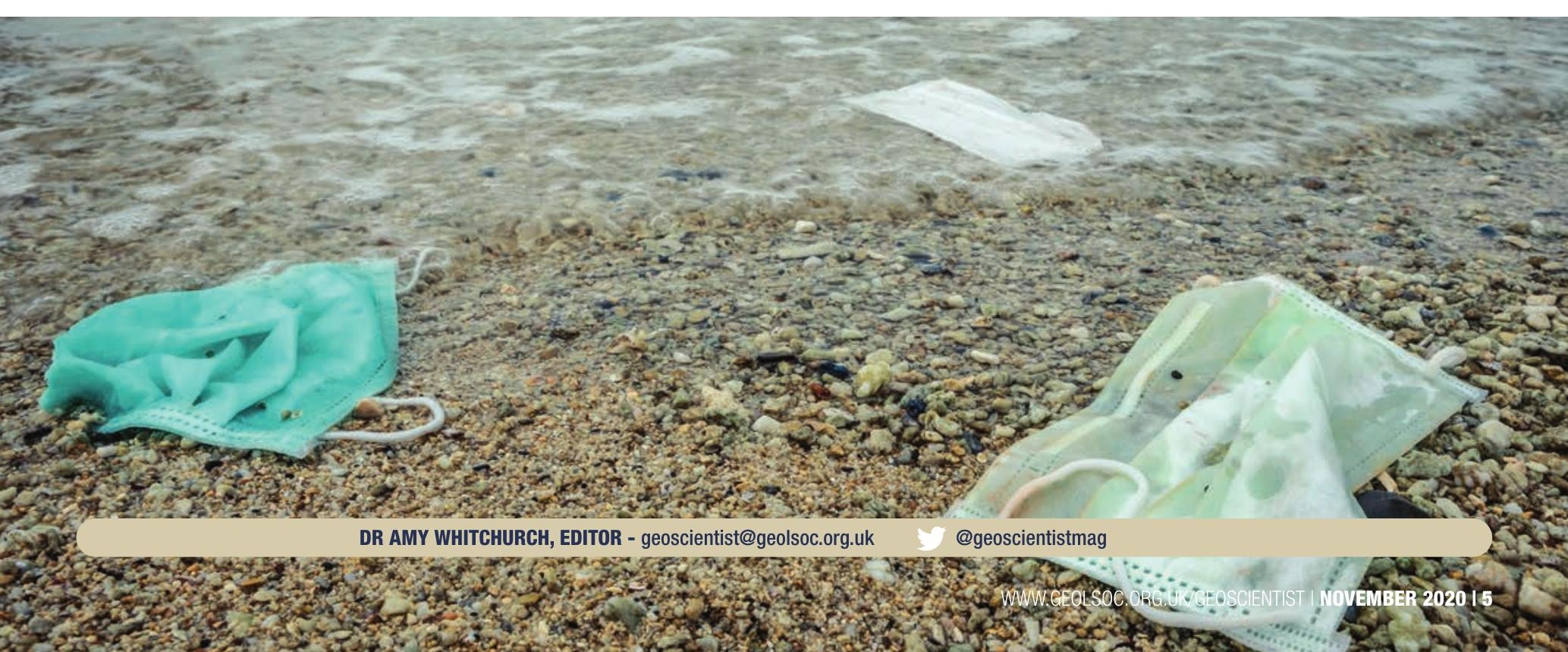

